BMJ Open

Diabetes

Research

\& Care

\title{
Obstructive sleep apnea in adults with type 1 and type 2 diabetes: perspectives from a quality improvement initiative in a university-based diabetes center
}

\author{
Simona loja, ${ }^{1}$ Eileen R Chasens, ${ }^{2}$ Jason $\mathrm{Ng},{ }^{3}$ Patrick J Strollo, ${ }^{4}$ Mary T Korytkowski ${ }^{5}$
}

To cite: loja S, Chasens ER, $\mathrm{Ng} \mathrm{J}$, et al. Obstructive sleep apnea in adults with type 1 and type 2 diabetes: perspectives from a quality improvement initiative in a universitybased diabetes center. BMJ Open Diab Res Care 2017;5:e000433. doi:10.1136/ bmjdrc-2017-000433

\section{- Additional material is} published online only. To view, please visit the journal online (http://dx.doi.org/10.1136/ bmjdrc-2017-000433)

Received 20 April 2017 Accepted 18 June 2017

\section{(a) CrossMark}

${ }^{1}$ Ohio Valley Medical Center, Wheeling, West Virginia, USA ${ }^{2}$ Department of Nursing, University of Pittsburgh, Pittsburgh, Pennsylvania, USA ${ }^{3}$ Department of Medicine, Division of Endocrinology, University of Pittsburgh Medical Center, Pittsburgh, Pennsylvania, USA

${ }^{4}$ Division of Allergy, Pulmonary and Critical Care Medicine, University of Pittsburgh, Pittsburgh, Pennsylvania, USA

${ }^{5}$ Department of Medicine, Division of Endocrinology and Metabolism, University of Pittsburgh, Pittsburgh, Pennsylvania, USA

Correspondence to Dr Mary T Korytkowski; mtk7@pitt.edu

\section{ABSTRACT}

Objective Obstructive sleep apnea (OSA) and diabetes are frequent comorbid conditions. Screening for OSA in patients with diabetes is recommended but the frequency with which this is done in clinical practice is unknown. The objectives of this quality improvement initiative were to identify clinician and patient perceptions regarding OSA and to identify the prevalence of patients at high risk for OSA (HROSA).

Methods A quality improvement initiative was conducted to query clinicians and patients attending a specialty diabetes clinic regarding attitudes and beliefs related to OSA. The Berlin Questionnaire was embedded in patient questionnaires to identify patients as low risk for OSA (LROSA) or HROSA.

Results 35 clinicians completed questionnaires with $>80 \%$ agreement that OSA contributed to blood pressure (BP), glycemic control, and diabetes complications and that screening is a shared responsibility with other physicians; but only $17 \%$ indicated regular screening due predominantly to insufficient time. Of 107 patients (26 type 1 diabetes mellitus (T1DM) and 81 type 2 diabetes mellitus (T2DM)), 30\% were aware that OSA could affect diabetes outcomes. The prevalence of known OSA, LROSA, and HROSA was similar in T1DM (15\%, 50\%, 35\%) and T2DM ( $36 \%, 33 \%, 31 \%$, respectively) ( $p=0.21) .59 \%$ of all HROSA patients indicated that OSA screening had never been discussed with them.

Conclusions These results demonstrate that providers, but not patients, are knowledgeable about the importance of OSA screening, but insufficient time is a major barrier to wider screening. Approximately, $30 \%$ of patients with T1DM and T2DM were identified as HROSA supporting the need for procedures that improve detection and treatment.

\section{INTRODUCTION}

Obstructive sleep apnea (OSA) is a disorder characterized by snoring, periods of hypopnea or apnea, and sleep fragmentation that is often associated with daytime sleepiness. ${ }^{1}$ OSA is prevalent in adults with diabetes, with highest rates observed among obese patients with type 2 diabetes mellitus (T2DM), but is increasingly recognized as occurring among those with type 1 diabetes mellitus (T1DM) as well. ${ }^{23}$

\section{Significance of this study}

What is already know about the subject?

- There is high prevalence of obstructive sleep apnea (OSA) among individuals with type 1 and 2 diabetes, but screening for this disorder is infrequently performed in primary care settings.

What are the new findings?

- Despite clinician awareness of the importance of OSA identification, screening for the condition is alsinfrequently performed in the endocrine practice setting.

- The patient population with diabetes has low awareness of the importance of OSA identification but a high interest in the learning more about this subject. There prevalence of patients identified as being at high risk for OSA (HROSA) was similar in patients with type 1 and type 2 diabetes.

How might these results change the ficus of research or clinical practice?

- This report highlights the need to implement collaborative pathways among various clinical specialties in order to best address OSA and improve the clinical care and outcomes of patients living with diabetes.

A strong incentive for screening patients with diabetes for OSA is related to the observed risk for morbidity and mortality from cardiovascular disease with each of these disorders. ${ }^{4-6}$ Individuals with comorbid diabetes and OSA have higher blood pressure (BP), poor sleep quality, lower health-related quality of life, and lower adherence to diabetes self-management practices; all of which improve with adequate treatment. ${ }^{7-9}$ While associations are observed between OSA severity and hemoglobin A1c (HbA1c), studies investigating changes in glycemic control with continuous positive airway pressure (CPAP) therapy report mixed results. ${ }^{10-13}$ Low levels of adherence to CPAP has been a limitation of many of the 
studies, with longer duration of nightly CPAP use being identified as a contributor to the ability to achieve the beneficial effects of CPAP treatment. ${ }^{1415}$

In the most recent standards of care, the American Diabetes Association recommends that clinicians maintain awareness of OSA as a comorbidity that affects overall diabetes management. ${ }^{16}$ This is consistent with the recommendations from other professional societies ${ }^{17}{ }^{18}$; however, OSA detection is infrequently addressed in clinical practice. Large discrepancies between expected and diagnosed cases of OSA in patients with diabetes have been reported, suggesting that the majority of patients at risk for OSA are not being identified. ${ }^{19}$ Endocrinologists provide care to a large percentage of patients with difficult to control diabetes which puts this group in a position to address this important comorbid condition. To our knowledge, OSA screening frequency and practices among endocrinologists in diabetes patient populations has not been previously explored. To address this, we designed a quality improvement (QI) initiative to define endocrinologist and patient opinions and perceptions regarding OSA identification and treatment. In addition, we sought to identify the prevalence of undiagnosed but high risk for OSA (HROSA) among patients with diabetes being seen in a university-based specialty diabetes practice.

\section{METHODS}

This project was reviewed by the University of Pittsburgh Institutional Review Board and approved as a QI initiative by the University of Pittsburgh Medical Center (UPMC) Quality Improvement Committee. Clinician and patient questionnaires were designed by the investigators (SI, PS, EC, MK). An 11-item survey for clinicians was designed to investigate knowledge, attitudes, barriers, and proposed solutions for addressing OSA in their diabetes patient population (see Appendix A in the online Supplementary file 1). An 18-item de-identified patient survey was designed to examine beliefs and interest relating to OSA, as well as to obtain information regarding a prior OSA diagnosis and treatment (see Appendix B in the online Supplementary file 1. The Berlin Questionnaire (BQ), a validated screening tool for OSA, was embedded in the patient questionnaire. ${ }^{20}$

To ensure anonymity of responses, de-identified provider questionnaires were distributed to attending physicians, nurse practitioners, physician assistants, and fellows in the Division of Endocrinology and Metabolism at UPMC. Patients were invited to complete a questionnaire at the end of a scheduled office visit to the UPMC Center for Diabetes and Endocrinology. Inclusion criteria were age $\geq 18$ years and a diagnosis of T1DM or T2DM. Exclusion criteria included pregnancy, gestational

\begin{tabular}{lllll}
\hline \multicolumn{1}{l}{ Table 1 Clinical characteristics according to OSA status } & & & \\
\hline & OSA & HROSA & LROSA & p Value \\
\hline $\mathrm{N}$ & 33 & 34 & 40 & \\
\hline Age (years) & $62.4 \pm 8.9$ & $53.1 \pm 13.8$ & $56.3 \pm 17.4$ & 0.03 \\
\hline Sex (female) & $58 \%$ & $56 \%$ & $60 \%$ & 0.94 \\
\hline BMI (kg/m ${ }^{2}$ ) & $36.5 \pm 8.1$ & $34.1 \pm 7.2$ & $29.9 \pm 7.5$ & $<0.01$ \\
\hline T2DM & $88 \%$ & $74 \%$ & $68 \%$ & 0.12 \\
\hline DM duration (years) & $14.7 \pm 12.7$ & $15.4 \pm 10.3$ & $17.8 \pm 10.9$ & 0.19 \\
\hline Retinopathy & $42 \%$ & $32 \%$ & $35 \%$ & 0.79 \\
\hline Nephropathy & $42 \%$ & $18 \%$ & $13 \%$ & $<0.01$ \\
\hline Neuropathy & $73 \%$ & $53 \%$ & $63 \%$ & 0.25 \\
\hline CAD & $9 \%$ & $6 \%$ & $18 \%$ & 0.26 \\
\hline CVA & $0 \%$ & $6 \%$ & $3 \%$ & 0.34 \\
\hline HTN & $91 \%$ & $82 \%$ & $65 \%$ & 0.02 \\
\hline SBP (mm Hg) & $137.2 \pm 20.8$ & $139.6 \pm 15.8$ & $138.3 \pm 3.2$ & 0.29 \\
\hline DBP (mm Hg) & $76.6 \pm 11.4$ & $79.5 \pm 10.9$ & $76.2 \pm 10.24$ & 0.40 \\
\hline Number of BP medications & $2.0 \pm 1.2$ & $1.8 \pm 1.2$ & $1.5 \pm 1.3$ & 0.19 \\
\hline HbA1C & $8.0 \pm 1.2 \%$ & $8.3 \pm 1.8 \%$ & $7.7 \pm 1.4 \%$ & 0.44 \\
\hline Number of non-insulin DM medications & $1.0 \pm 0.9$ & $1.1 \pm 0.9$ & $0.8 \pm 0.9$ & 0.37 \\
\hline Insulin therapy & $64 \%$ & $88 \%$ & $85 \%$ & 0.02 \\
\hline Insulin TDD (units/kg) & $0.7 \pm 0.5$ & $0.9 \pm 0.5$ & $0.6 \pm 0.5$ & 0.02 \\
\hline
\end{tabular}

Data are presented as means \pm SD.

$\mathrm{BP}$, blood pressure; BMI, body mass index; CAD, coronary artery disease; CVA, cerebral vascular accident; DBP, diastolic blood pressure; DM, diabetes mellitus; Hb1AC, hemoglobin A1C; HROSA, high risk for OSA; HTN, hypertension; LROSA, low risk for OSA; OSA, obstructive sleep apnea; SBP, systolic blood pressure; T2DM, type 2 diabetes mellitus; TDD, total daily dose. 
Table 2 Clinician and patient perceptions of OSA-DM relationship

\begin{tabular}{|c|c|c|c|c|c|c|}
\hline \multirow[b]{2}{*}{ Statement } & \multicolumn{3}{|c|}{ Providers } & \multicolumn{3}{|c|}{ Patients } \\
\hline & Agree & Disagree & Uncertain & Agree & Disagree & Uncertain \\
\hline OSA is prevalent in T2DM & $97 \%$ & $0 \%$ & $3 \%$ & $\mathrm{~N} / \mathrm{A}$ & & \\
\hline $\begin{array}{l}\text { OSA treatment could positively impact BP } \\
\text { control }\end{array}$ & $94 \%$ & $0 \%$ & $6 \%$ & $30 \%$ & $4 \%$ & $66 \%$ \\
\hline $\begin{array}{l}\text { OSA treatment could positively impact } \\
\text { glycemic control }\end{array}$ & $83 \%$ & $0 \%$ & $17 \%$ & $28 \%$ & $6 \%$ & $66 \%$ \\
\hline $\begin{array}{l}\text { OSA treatmentcould positively impact DM } \\
\text { complications }\end{array}$ & $83 \%$ & $0 \%$ & $17 \%$ & $\mathrm{~N} / \mathrm{A}$ & & \\
\hline
\end{tabular}

BP, blood pressure; DM, diabetes mellitus; N/A not asked; OSA, obstructive sleep apnea; T2DM, type 2 diabetes mellitus.

diabetes, and known monogenic forms of diabetes. Electronic medical record (EMR) verification was performed in patients who reported a diagnosis of OSA. For patients who reported a prior diagnosis of OSA, treatment adherence was defined by patient report of $>4$ hours of treatment use every night. In patients without known OSA, BQ scores were used to identify those at low risk for OSA (LROSA) or HROSA. ${ }^{20} 21$ All clinical data including information regarding microvascular and macrovascular complications current to the time of survey completion was obtained from the EMR. All patient data were de-identified prior to analysis.

\section{Statistical analyses}

Patient participants were divided according to OSA status: known OSA, LROSA, HROSA and according to type of diabetes. All analyses were performed in GraphPad Prism V.6.0. One-way analysis of variance or Kruskal-Wallis test with post-test Dunn's multiple comparison were performed for comparison of continuous variables among the three groups. Unpaired Student's t-test or Mann-Whitney non-parametric test were used for two groups comparisons. Comparison of categorical variables was performed with $\mathrm{X}^{2}$ or Fisher's exact test. In all cases, two-sided $\mathrm{p}$ values are reported.

\section{RESULTS}

The provider survey was completed by 35 clinicians: 21 attending endocrinologists, four advanced practice providers, and 10 endocrinology fellows. The patient questionnaire was completed by 107 of 125 patients invited to participate (18 patients declined and no data were collected). The clinical characteristics of patient participants were grouped according to known OSA $(n=33)$, LROSA $(n=40)$, and HROSA $(n=34)$ (table 1$)$. Those with known OSA were older than HROSA, more obese than LROSA, with a higher prevalence of nephropathy and hypertension, and lower use of insulin therapy than HROSA or LROSA. HROSA patients used higher insulin doses than LROSA. There were no group differences for sex, type or duration of diabetes, HbA1c, BP, number of antihypertensive or non-insulin diabetes medications.

\section{Provider and patient perceptions}

There was significant discrepancy between provider and patient responses regarding the prevalence and importance of OSA screening and treatment (table 2). The majority of clinician respondents agreed that OSA is prevalent in individuals with T2DM, that treatment can favorably impact control of BP, control of diabetes mellitus (DM), and risk for DM- related complications and that the responsibility for screening is shared with primary care physicians (PCP) (88\%). However, $17 \%$, $69 \%$, and $14 \%$ indicated that they always, sometimes, rarely or never asked questions about OSA symptoms. Screening was reported more frequently for patients who were obese, independent of type of diabetes (74\%) or who had T2DM with $(54 \%)$ or without $(11 \%$ obesity. The most frequently described screening method was a clinical interview with $6 \%$ reporting use of a validated screening questionnaire (specific tool not identified).

The most frequently reported barriers to screening included lack of time (52\%), insufficient knowledge about how to refer for testing (16\%) or treatment (29\%), inability to interpret test results (29\%), and anticipated poor treatment adherence (10\%). Suggested methods to increase screening included having guidelines from professional societies $(60 \%)$ or specific to the practice setting (40\%) with an explanation of referral pathways $(49 \%)$, scientific updates on the topic $(46 \%)$, and workshops on the basics of sleep medicine (29\%).

\section{Patient responses}

The majority of patient respondents had T2DM $(n=81)$. When compared with those with T1DM $(n=26)$, those with T2DM were older (T2DM vs T1DM: $61.4 \pm 10.6$ vs $44.1 \pm 17.0$ years, $\mathrm{p}<0.01$ ), more obese (BMI $34.9 \pm 8.2$ vs $\left.28.2 \pm 4.9 \mathrm{~kg} / \mathrm{m}^{2}, \mathrm{p}<0.01\right)$ with a shorter duration of diabetes $(13.3 \pm 8.2$ vs $24.7 \pm 14.9$ years, $\mathrm{p}<0.01)$. No differences were observed in sex $(54.3 \%$ vs $69.2 \%$ female, $\mathrm{p}=0.25)$ or percentage with known OSA $(36 \%$ vs $15 \%)$, LROSA (33\% vs $50 \%) \quad(\mathrm{p}=0.12)$, or HROSA $(31 \%$ vs $35 \%)$.

The majority of all diabetes patients without OSA $(75 \%$ of LROSA, 59\% of HROSA) reported that OSA had never been discussed with them. Patients who reported that 
this had been discussed, identified their PCP (44\%) as the provider of information, followed by pulmonologists (26\%) and endocrinologists (24\%).

Only a small percentage of patients reported awareness of potential benefits of OSA treatment (table 2). Patients with known OSA were more aware -than the other groups of the benefits forBP control(52\% vs $21 \%$ vs $20 \%, \mathrm{p}<0.01)$ and glycemic control $(45 \%$ vs $24 \%$ vs $18 \%, \mathrm{p}=0.03)$. Among those with known OSA, treatment adherence was low (45\%). Those reporting knowledge of OSA treatment benefits - on BP (OR 5.5, 95\% CI 1.2 to 24.8, $\mathrm{p}=0.04$ ) and glycemic control (OR 9.65, 95\% CI 1.9 to $47.4, \mathrm{p}<0.01$ ) were more likely to be adherent to OSA treatment.

Patients with HROSA and LROSA status indicated a willingness to be evaluated ( $97 \%$ and $88 \%, \mathrm{p}=0.22)$ and treated for OSA ( $94 \%$ and $90 \%, \mathrm{p}=0.69)$. No queries were conducted for treatment preferences, such as CPAP or other treatments (eg, oral appliances, surgery). The majority of OSA and HROSA but not LROSA participants expressed interest in learning more about this disorder ( $66 \%$ vs $65 \%$ vs $37 \%$, $\mathrm{p}=0.02)$.

\section{DISCUSSION}

These results indicate that there was no structured approach to OSA screening in a high-risk population with diabetes at this center. Insufficient time and lack of clear guidelines for screening and diagnosis on the part of providers and low awareness on the part of patients were identified as main contributors. The observation that a third of patients with T1DM and T2DM could be considered as HROSA based on results of the BQ emphasizes a need to improve awareness and screening practices. The observed low rates of OSA screening in the current report are similar to previous reports in other study populations. ${ }^{19}$ In a UK-based nationwide survey of healthcare professionals providing care for patients with T2DM, the majority of respondents $(68 \%)$ were not aware of OSA screening recommendations, and $81 \%$ reported that they did not routinely assess for OSA as part of their practice. $^{22}$ The interpretation of these results is limited by a very low response rate to the survey $(n=62)$.

Obesity, independent of type of diabetes, was identified by providers as an indicator for OSA screening. This is congruent with the observations that obesity is one of the strongest risk factors for OSA and that OSA symptoms can improve or resolve with weight loss interventions. ${ }^{23} 24$ While the prevalence of obesity is recognized as high in the T2DM population, the trend toward obesity is also observed in those with T1DM. ${ }^{25}{ }^{26}$ Among the few studies in the literature addressing the occurrence of OSA in patients with T1DM, the prevalence of OSA diagnosed using polysomnography was $47 \%$ among 67 consecutive patients with T1DM. ${ }^{27}$ Those with OSA had longer duration of diabetes and more microvascular and macrovascular complications, but not a higher BMI, compared with patients without OSA in this study, making obesity alone an unreliable indicator for screening. Although the number of participants with T1DM in this study is small, these results support the need for additional attention to underlying OSA in this group of patients.

PCPs were identified as being most likely to provide patients with information regarding OSA. In this study, all participants were under the care of a PCP as well as an endocrinologist. The majority of clinicians reported that OSA screening is a shared responsibility with PCPs, suggesting that a collaborative care model that provides tools that address the described barriers could increase the frequency of OSA screening. ${ }^{28}$ Educational sessions directed toward providers with prompts in the EMR for evaluation of suspected OSA could prove useful and have previously been shown to have various degrees of success in similar conditions. ${ }^{29}$ Strategies that increase patient awareness have also been demonstrated to be effective at influencing provider behavior in other disease models. ${ }^{30}$

OSA treatment adherence of $>4$ hours / night was self-reported by $45 \%$ of patients with OSA, consistent with prior reports. ${ }^{31}$ Although the sample size of the current study was small and the CIs large, there were positive associations between patient beliefs in the positive effects of OSA treatment and treatment adherence, emphasizing the importance of patient education as a way of improving health outcomes. ${ }^{32}$ It was encouraging to find that patients with OSA and HROSA were interested in obtaining more information which could potentially improve treatment adherence and outcomes. ${ }^{15} 33$

There are several limitations to this project. One is that the results are derived from clinicians and patients at a single academic center which may not reflect perceptions or prevalence information at other institutions or practice settings. Due to anonymity of surveys, we were not able to assess differences among clinicians who focus their practice on diabetes compared with other subspecialty areas within endocrine practice. Other limitations include small sample size and the absence of information relating to patient ethnicity or level of education.

This initiative was conducted as a collaborative QI program designed to gather data regarding current practices of screening patients with diabetes for OSA. Since this project was completed, an order set for referral of patients for home sleep testing has been introduced into the EMR. Additional testing to determine the frequency with which this order set is used is planned.

In summary, this investigation demonstrated that providers are knowledgeable of the importance of screening patients with diabetes for OSA but it is important that identified barriers be addressed as a way of improving current screening frequency. The low awareness of the OSA-DM interaction on the part of patients can be addressed through public awareness campaigns. This report highlights that there is a need to implement clear collaborative pathways directed at engaging providers across disciplines as well as patients in addressing OSA as a way of improving the quality of diabetes care and patient outcomes. 
Acknowledgements The authors would like to thank Dr Linda Siminerio and Dr Michelle Griffith for their insightful suggestions toward the patient questionnaire design and to Carley Stoy PA and the certified diabetes educators for their help in survey administration. We thank all endocrinology clinicians and patients for offering their time to complete the provider survey and to invite their patients to participate in this quality improvement initiative.

Competing interests MTK has served on an advisory board for Novo Nordisk. PJS discloses the following research grant support: R01 HL107370, R01 DK096028302, R01 HL120354301A1, 1UH2HL125103301, 5UL1TR000005309, PA DOH MD3023384 and American Sleep Medicine Foundation and the following industry relations: Philips 3 Respironics, ResMes, Inspire Medical Systems, PinMed, NFL, Emmi Solutions and Jazz Pharmaceuticals. SI, JN and EC have no conflict of interests to declare.

Ethics approval All procedures performed in studies involving human participants were in accordance with the ethical standards of the institutional and/or national research committee and with the 1964 Helsinki declaration and its later amendments or comparable ethical standards.

Provenance and peer review Not commissioned; internally peer reviewed.

Open Access This is an Open Access article distributed in accordance with the Creative Commons Attribution Non Commercial (CC BY-NC 4.0) license, which permits others to distribute, remix, adapt, build upon this work non-commercially, and license their derivative works on different terms, provided the original work is properly cited and the use is non-commercial. See: http://creativecommons.org/ licenses/by-nc/4.0/

(C) Article author(s) (or their employer(s) unless otherwise stated in the text of the article) 2017. All rights reserved. No commercial use is permitted unless otherwise expressly granted.

\section{REFERENCES}

1. Epstein LJ, Kristo D, Strollo PJ, et al. . Clinical guideline for the evaluation, management and long-term care of obstructive sleep apnea in adults. J Clin Sleep Med 2009;5:263-76.

2. Schober AK, Neurath MF, Harsch IA. Prevalence of sleep apnoea in diabetic patients. Clin Respir J 2011;5:165-72.

3. Foster GD, Sanders MH, Millman R, et al. . Obstructive sleep apnea among obese patients with type 2 diabetes. Diabetes Care 2009;32:1017-9.

4. American Diabetes Association. Cardiovascular disease and risk management. Diabetes Care 2016;39:S60-S71.

5. Kendzerska T, Gershon AS, Hawker G, et al. Obstructive sleep apnea and risk of cardiovascular events and all-cause mortality: a decade-long historical cohort study. PLoS Med 2014;11:e1001599.

6. Cheung YY, Tai BC, Loo G, et al. Screening for obstructive sleep apnea in the assessment of coronary risk. Am J Cardiol 2017;119:996-1002.

7. Montesi SB, Edwards BA, Malhotra A, et al. The effect of continuous positive airway pressure treatment on blood pressure: a systematic review and meta-analysis of randomized controlled trials. J Clin Sleep Med 2012;8:587-96.

8. Siccoli MM, Pepperell JC, Kohler M, et al. Effects of continuous positive airway pressure on quality of life in patients with moderate to severe obstructive sleep apnea: data from a randomized controlled trial. Sleep 2008;31:1551-8.

9. Chasens ER, Korytkowski M, Sereika SM, et al. Effect of poor sleep quality and excessive daytime sleepiness on factors associated with diabetes self-management. Diabetes Educ 2013;39:74-82.

10. Aronsohn RS, Whitmore $\mathrm{H}$, Van Cauter $\mathrm{E}$, et al. Impact of untreated obstructive sleep apnea on glucose control in type 2 diabetes. Am J Respir Crit Care Med 2010;181:507-13.

11. Morariu EM, Chasens ER, Strollo PJ, et al. Effect of continuous positive airway pressure (CPAP) on glycemic control and variability in type 2 diabetes. Sleep Breath 2017;21:145-7.

12. West SD, Nicoll DJ, Wallace TM, et al. Effect of CPAP on insulin resistance and $\mathrm{HbA} 1 \mathrm{c}$ in men with obstructive sleep apnoea and type 2 diabetes. Thorax 2007;62:969-74.
13. Shaw JE, Punjabi NM, Naughton MT, et al. The effect of treatment of obstructive sleep apnea on glycemic control in type 2 diabetes. Am $J$ Respir Crit Care Med 2016;194:486-92.

14. Myhill PC, Davis WA, Peters KE, et al. Effect of continuous positive airway pressure therapy on cardiovascular risk factors in patients with type 2 diabetes and obstructive sleep apnea. $J$ Clin Endocrinol Metab 2012;97:4212-8.

15. Mokhlesi B, Grimaldi D, Beccuti G, et al. Effect of one week of CPAP treatment of obstructive sleep apnoea on 24-hour profiles of glucose, insulin and counter-regulatory hormones in type 2 diabetes. Diabetes Obes Metab 2017;19:452-6.

16. American Diabetes Association. Comprehensive medical evaluation and assessment of comorbidities. Diabetes Care 2017;40:S25-S32.

17. Handelsman Y, Bloomgarden ZT, Grunberger G, et al. American association of clinical endocrinologists and american college of endocrinology - clinical practice guidelines for developing a diabetes mellitus comprehensive care plan - 2015. Endocr Pract 2015;21(Suppl 1):1-87.

18. Shaw JE, Punjabi NM, Wilding JP, et al. . Sleep-disordered breathing and type 2 diabetes: a report from the International Diabetes Federation Taskforce on epidemiology and prevention. Diabetes Res Clin Pract 2008;81:2-12.

19. Heffner JE, Rozenfeld Y, Kai M, et al. Prevalence of diagnosed sleep apnea among patients with type 2 diabetes in primary care. Chest 2012;141:1414-21.

20. Netzer NC, Stoohs RA, Netzer CM, et al. Using the Berlin questionnaire to identify patients at risk for the sleep apnea syndrome. Ann Intern Med 1999;131:485-91.

21. Senthilvel E, Auckley D, Dasarathy J. Evaluation of sleep disorders in the primary care setting: history taking compared to questionnaires. $J$ Clin Sleep Med 2011;7:41-8.

22. Seetho IW, O?Brien SV, Hardy KJ, et al. Obstructive sleep apnoea in diabetes - assessment and awareness. Br J Diabetes 2014;14:105-8

23. Schwartz AR, Patil SP, Laffan AM, et al. Obesity and obstructive sleep apnea: pathogenic mechanisms and therapeutic approaches. Proc Am Thorac Soc 2008;5:185-92.

24. Foster GD, Borradaile KE, Sanders $\mathrm{MH}$, et al. A randomized study on the effect of weight loss on obstructive sleep apnea among obese patients with type 2 diabetes: the Sleep AHEAD study. Arch Int Med 2009;169:1619-26.

25. Conway B, Miller RG, Costacou T, et al. Temporal patterns in overweight and obesity in type 1 diabetes. Diabet Med 2010;27:398-404.

26. Maggio CA, Pi-Sunyer FX. Obesity and type 2 diabetes. Endocrinol Metab Clin North Am 2003;32:805-22.

27. Manin G, Pons A, Baltzinger P, et al. Obstructive sleep apnoea in people with type 1 diabetes: prevalence and association with microand macrovascular complications. Diabet Med 2015;32:90-6.

28. Finkel KJ, Searleman AC, Tymkew $\mathrm{H}$, et al. Prevalence of undiagnosed obstructive sleep apnea among adult surgical patients in an academic medical center. Sleep Med 2009;10:753-8.

29. Sequist TD, Gandhi TK, Karson AS, et al. A randomized trial of electronic clinical reminders to improve quality of care for diabetes and coronary artery disease. J Am Med Inform Assoc 2005;12:431-7.

30. Sriphanlop P, Hennelly MO, Sperling D, et al. Increasing referral rate for screening colonoscopy through patient education and activation at a primary care clinic in New York City. Patient Educ Couns 2016;99:1427-31.

31. Weaver TE, Grunstein RR. Adherence to continuous positive airway pressure therapy: the challenge to effective treatment. Proc Am Thorac Soc 2008;5:173-8.

32. Sawyer AM, Deatrick JA, Kuna ST, et al. Differences in perceptions of the diagnosis and treatment of obstructive sleep apnea and continuous positive airway pressure therapy among adherers and nonadherers. Qual Health Res 2010;20:873-92.

33. Mokhlesi B, Grimaldi D, Beccuti G, et al. Effect of one week of 8-hour nightly continuous positive airway pressure treatment of obstructive sleep apnea on glycemic control in type 2 diabetes: a proof-of-concept study. Am J Respir Crit Care Med 2016;194:516-9. 